\title{
What correlation does not tell you about hedge funds: A factor approach to hedge fund correlations
}

\author{
Jean-François Bacmann, Pierre Jeanneret*, and Stefan Scholz \\ *RMF Investment Management, Huobstrasse 16, Pfaeffikon SZ CH-8808, Switzerland. \\ Tel: + 4155417 7710,Fax: + 4155417 7711,E-mail: pierre.jeanneret@rmf.ch
}

Received (in revised form): 22nd November, 2007

Jean-François Bacmann is deputy head of the quantitative analysis group of RMF Investment Management, based in Pfäffikon, Switzerland.

Pierre Jeanneret is a member of the quantitative analysis group of RMF Investment Management, based in Pfäffikon, Switzerland.

Stefan Scholz is head of the quantitative analysis group of RMF Investment Management and member of the RMF Management Committee, based in Pfäffikon, Switzerland.

\section{Practical applications}

Correlation measures the relationship between two time series from a static perspective. We introduce a methodology to measure the drivers of correlations between the returns of a dynamic strategy (hedge funds) and those of a static benchmark (traditional investments). Our approach explains why correlations between hedge funds and traditional investments are sometimes high and at other times low. Furthermore we highlight which elements of hedge funds' strategies are responsible for making correlations vary over time. It constitutes an improvement in measuring the diversification potential of hedge funds to traditional investments.

\begin{abstract}
Measured correlations between hedge fund returns and world equities are currently very high, prompting some pundits to question the diversification benefits of hedge funds. We show that this correlation is a short-term phenomenon driven by the pursuit of absolute returns by hedge funds. Measured correlations provide a very limited understanding of the relationship between a dynamic trading strategy and passive investment benchmarks. We estimate the performance contributions of alternative risk factors and show that they drive the evolution of hedge fund correlations to traditional investments. In addition, we observe that the non-alternative components of hedge fund performance
\end{abstract}

exhibit more stable relationships with traditional investments. Our analysis clearly refutes the hypothesis that hedge funds have lost their diversification benefits. Journal of Derivatives \& Hedge Funds (2008) 14, 90-101. doi:10.1057/jdhf.2008.10

Keywords: hedge funds; alternative risk factors; correlation; diversification; factor model

\section{INTRODUCTION}

Hedge funds have attracted significant amounts of capital in the last few years, mainly because of their primary performance characteristics:
Journal of Derivatives \& Hedge Funds, Vol. 14 No. 2, 2008 , pp. 90-101 (C) 2008 Palgrave Macmillan Ltd 1753-9641 
absolute returns and low correlation to traditional investments. This powerful combination helps to increase the profitability of traditional portfolios while mitigating their risk. The measured correlation between hedge funds and traditional investments has, however, increased over the last three years, which has led some investment professionals to question the diversification benefits of hedge funds on an ongoing basis. Yet hedge fund managers display particular skills trading derivative instruments dynamically in specific markets, which can often be exotic. As a consequence, streams of returns generated by hedge fund strategies are not normally distributed, and have nonlinear relationships with traditional investments. At this point, two conflicting hypotheses can explain the current situation:

(a) Hedge funds are no longer providing diversification from traditional investments.

(b) The dynamic behaviour of hedge funds is driving the correlations to traditional investments up to their current level.

We show in this paper that the current level of correlations is derived from the correlation measure itself. Correlation is a static view of the relationship between two series. Hedge funds are dynamic in their investment strategies and their risk allocation. Consequently, their relationship to traditional investments is also dynamic.

Measured correlations thus provide limited insight into the diversification potential of hedge funds over a short period of time.

In order to test the two hypotheses, we need to address the limits of correlations as the measure of the relationship between hedge funds and traditional investments. We develop a framework to decompose hedge fund returns and to identify their dynamic drivers. Thereafter, we show how the measured correlations between hedge funds and traditional investments are driven by the dynamic strategies applied by hedge funds. Our results reject the hypothesis that hedge funds are no longer providing diversification. They clearly support the fact that hedge fund diversification benefits stem from hedge funds' dynamic ability to adjust to market conditions.

\section{The 'perfect timing' hedge fund strategy}

In the manner of Lo ${ }^{1}$, we use a hypothetical hedge fund strategy to illustrate the implication of dynamic trading on measured correlations. Lo's Capital Decimation Partners hedge funds show the impact of derivative trading on performance and also the limitations of position transparency in understanding a dynamic strategy. In our example, the hypothetical hedge fund strategy is built to emphasise the limitations of static measures of risk when applied to a dynamic trading system. Consider a strategy that gives a signal to go long the stock market when its future monthly performance is positive, and a signal to short the stock market when its future monthly performance is negative. Obviously, this strategy would be based on perfect stock market predictions - a 'perfect timing' hedge fund strategy. We measured the 24-month rolling correlations between the time series of monthly returns of the 'perfect timing' hedge fund strategy and the monthly performance of the MSCI World Index. Results over the period January 1994-July 2007 are presented in Figure 1.

The measured correlations are time-varying. They evolve in line with the trading strategy. They increase when the strategy is long the 


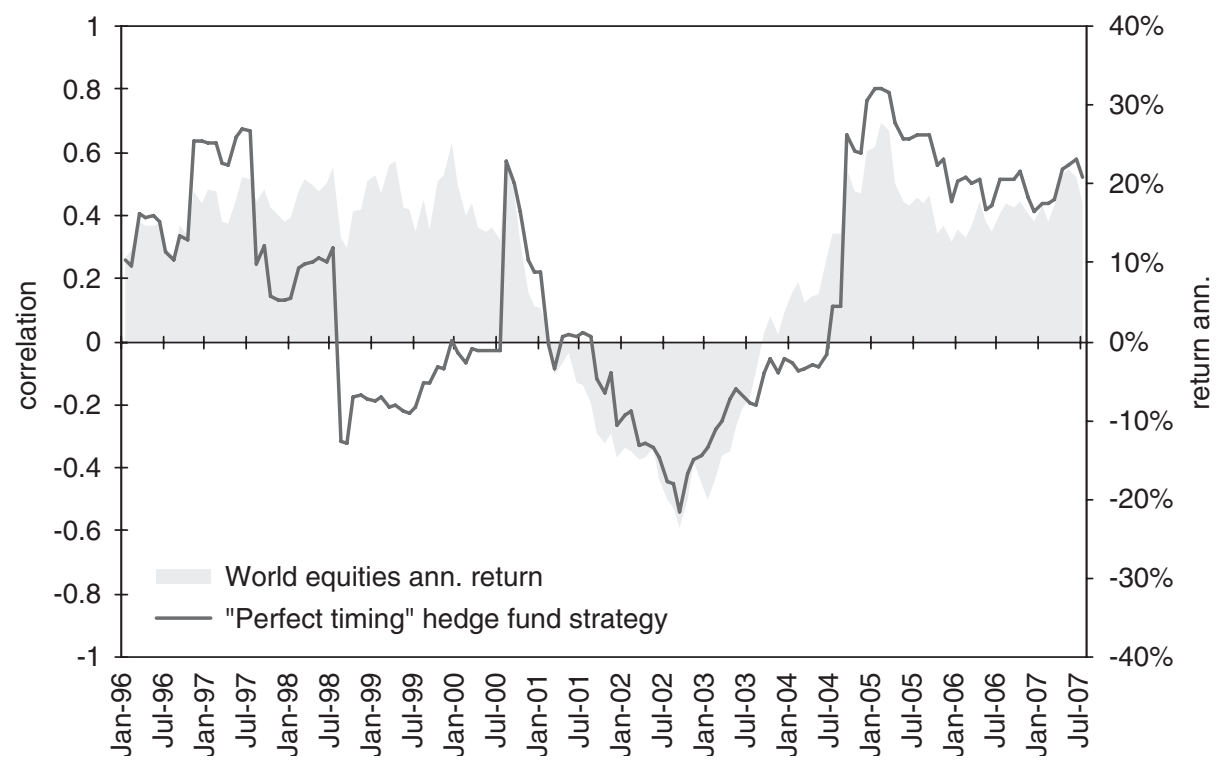

Figure 1: Twenty-four-month rolling correlations of the 'perfect timing' hedge fund strategy to world equities

market and they decrease when the strategy is short. Although they vary over time, they, however, still do not capture the true relationship between the two series of returns. By construction, the instantaneous correlation is either +1 or -1 . The correlation during negative months for world equities should be equal to -1 , making the 'perfect timing' hedge fund strategy a 'perfect' diversifier to equity market risk at any point in time.

This simple example illustrates the limitations of correlation in a dynamic trading environment. It does not mean that we can no longer use measured correlation, but that we have to do so in a more sophisticated way. Hedge fund returns are dynamically driven by underlying risk factors which themselves could be dynamic.

Additionally, hedge funds dynamically manage their allocation to the underlying risk factors. In order to take these dynamics into account, we have to identify and isolate the dynamic drivers of hedge fund returns before using them as correlation drivers. Formally, we test whether measured correlations between hedge funds and traditional investments are driven by the dynamic component of hedge fund returns.

\section{Identifying the dynamic component of hedge fund returns}

\section{The factor decomposition model}

Hedge fund returns are exposed to systematic sources of risk ${ }^{2}$. We measure these exposures by estimating the link between hedge fund returns and underlying risk factors. The factor decomposition model is more sophisticated in the context of hedge funds than it is for traditional investments. Hedge fund returns are decomposed into three elements: (1) contribution of traditional risk factors, (2) contribution of alternative risk factors, and (3) alpha. The contribution of traditional risk factors 
captures the part of hedge fund returns stemming from exposures to risk factors common to traditional investments (stock indices, interest rates, etc). The contribution of alternative risk factors captures the hedge fund strategy-specific portion of returns. Alternative risk factors aim to replicate the dynamic strategies of hedge funds on equities, fixed income, currencies, and commodities ( $\operatorname{see}^{3-6}$ for examples of alternative risk factors). These factors are expected to be important contributors to hedge fund returns. Finally, alpha is the proxy for hedge fund managers' skill in implementing, operating, and managing their strategies.

The factor decomposition model used in this section is based on the work done by Bacmann and Jeanneret ${ }^{7}$ on funds of hedge funds. A 12factor version of the model is used to explain the returns of the broad hedge fund strategies. It consists of the following multivariate regression:

$$
R_{i, t}=\alpha_{i}+\sum_{n} \beta_{i, n}^{\text {trad }} R_{n, t}^{\text {trad }}+\sum_{m} \beta_{i, m}^{\text {alter }} R_{m, t}^{\text {alter }}+\varepsilon_{i, t}
$$

where $R_{i, t}$ is the return on index $i$ in month $t, \alpha_{i}$ is the alpha component of index $i$ 's performance, $\beta_{i, n}^{\text {trad }}$ is the beta of index $i$ to traditional risk factor $n, R_{n, t}^{\text {trad }}$ is the return on traditional risk factor $n$ in month $t, \beta_{i, m}^{\text {alter }}$ is the beta of index $i$ to alternative risk factor $m, R_{m, t}^{\text {alter }}$ is the return on alternative risk factor $m$ in month $t, \varepsilon_{i, t}$ is a iid error term.

Table 1 presents the set of traditional and alternative risk factors ${ }^{7,8}$ that are used in the regression. Hedge funds are characterised by different investment styles. Therefore, we consider five non-overlapping hedge fund (hereafter HF) style indices taken from HFRI and Daniel B. Stark: HFRI Equity Hedge (HFRI EH), HFRI Relative Value Arbitrage
(HFRI RVA), HFRI Event-Driven (HFRI ED), HFRI Macro, and the Stark 300 Trader Index (Stark MF) as a proxy for managed futures. The five HF style indices allow us to capture the differences in risk-return characteristics and correlation structures stemming from specific investment strategies.

Traditional markets are represented by two international indices. The MSCI World Total Return Index (MSCI World) is the proxy for world equities and the Citigroup World Government Bond Index (Citigroup WGBI) is the proxy for world bonds. MSCI World is a free float-adjusted market capitalisation index combining 23 developed countries. Citigroup WGBI consists of about 670 bonds issued by 22 developed countries worldwide.

\section{Static risk profile of hedge fund style indices}

The period of analysis (January 1994-July 2007) includes a structural breakpoint in the multifactor regression framework (see Bacmann and Jeanneret $^{7}$, and Fung and Hsieh) ${ }^{2}$. In order to avoid stationarity problems, we identify two distinct time periods for the regression: January 1994-December 1999 (regression results presented in Table 2), and May 2000-July 2007 (regression results presented in Table 3).

The factor decomposition analysis leads to three main findings:

1 Alternative risk factors can significantly improve the explanatory power of the model. Their contribution increases during the second sub-period.

2 Our set of risk factors enables us to capture the differences in risk profile across hedge fund investment styles and over time. 
Table 1: Set of risk factors

\begin{tabular}{|c|c|c|c|}
\hline \multicolumn{2}{|c|}{ Traditional risk factors } & \multicolumn{2}{|l|}{ Alternative risk factors } \\
\hline MSCI World & $\begin{array}{l}\text { World aggregate of stock } \\
\text { market returns }\end{array}$ & $\begin{array}{l}\text { Momentum } \\
\text { spread }\end{array}$ & $\begin{array}{l}\text { Long past good performers and short past bad } \\
\text { performers. Look back horizon is last } 12 \\
\text { months }\end{array}$ \\
\hline $\begin{array}{l}\text { MSCI World } \\
\text { past } \\
\text { performance }\end{array}$ & $\begin{array}{l}\text { Performance of MSCI } \\
\text { World compounded over } \\
\text { the last } 12 \text { months }\end{array}$ & Contrarian spread & $\begin{array}{l}\text { Long recent bad performers and short recent } \\
\text { good performers. Recent is last month }\end{array}$ \\
\hline Size spread & $\begin{array}{l}\text { Long small caps and } \\
\text { short large caps }\end{array}$ & $\begin{array}{l}\text { Trend following } \\
\text { (TF) equities }\end{array}$ & $\begin{array}{l}\text { Factor that captures naïve trend following } \\
\text { strategies on a basket of stock market index } \\
\text { futures }\end{array}$ \\
\hline Value spread & $\begin{array}{l}\text { Long-value firms and } \\
\text { short-growth firms }\end{array}$ & TF interest rates & $\begin{array}{l}\text { Factor that captures naïve trend following } \\
\text { strategies on a basket of bond and short-term } \\
\text { interest rate futures }\end{array}$ \\
\hline \multirow[t]{3}{*}{$\begin{array}{l}\text { Change in } \\
\text { LTIR }\end{array}$} & $\begin{array}{l}\text { Change in the } 10 \text {-year } \\
\text { US Government yield } \\
\text { (Long-term interest rate) }\end{array}$ & TF currencies & $\begin{array}{l}\text { Factor that captures naïve trend following } \\
\text { strategies on a basket of foreign exchange } \\
\text { futures }\end{array}$ \\
\hline & & TF commodities & $\begin{array}{l}\text { Factor that captures naïve trend following } \\
\text { strategies on a basket of commodity futures }\end{array}$ \\
\hline & & $\begin{array}{l}\text { Change in } \mathrm{HY} \\
\text { spreads }\end{array}$ & $\begin{array}{l}\text { Change in the spread between CSFB High } \\
\text { Yield and 10-year US Government yield }\end{array}$ \\
\hline
\end{tabular}

3 Risk exposures are time-varying, outlining the ability of hedge fund managers to adjust their risk exposures to market conditions.

Alternative risk factors should capture, at least partially, the dynamic component of hedge fund returns. We test their joint significance in the regression by performing an F-Test under the null hypothesis that all their betas are equal to zero. The bottom rows of Tables 2 and 3 show the explanatory power of the regression on the full set of risk factors, the explanatory power of the regression on the set of traditional risk factors, and the F-statistic of the joint significance of all alternative risk factors. The added value of alternative risk factors in explaining hedge fund returns is important and it increases in the second sub-period (see Table 3).

The F-test rejects the hypothesis that all the alternative betas are equal to zero at the 1 per cent level, except for HFRI EH during the first sub-period. HFRI EH exhibits the least exposure to alternative risk factors during the first sub-period, which is characterised by a strong equity bull market (Tech Bubble). Most of the risk exposure thus comes from the stock market index and the size spread.

Overall, alternative risk factors greatly improve the explanatory power of the model. Their significance during the second sub-period, 
Table 2: Regression results — January 1994-December 1999

\begin{tabular}{|c|c|c|c|c|c|c|}
\hline $\begin{array}{l}\text { Risk factors ( } T=\text { traditional, } A=\text { alternative }) \\
\text { Alpha annualised }\end{array}$ & & $\begin{array}{l}\text { HFRI EH } \\
12.42 \%{ }^{\mathrm{a}}\end{array}$ & $\begin{array}{l}\text { HFRI RVA } \\
5.24 \% \mathrm{~b}\end{array}$ & $\begin{array}{l}\text { HFRI ED } \\
9.84 \% \text { b }\end{array}$ & $\begin{array}{l}\text { HFRI Macro } \\
6.56 \%\end{array}$ & $\begin{array}{l}\text { Stark } M F \\
3.82 \%\end{array}$ \\
\hline \multicolumn{7}{|l|}{ Equity risk } \\
\hline MSCI World & $\mathrm{T}$ & $0.335^{\mathrm{a}}$ & 0.057 & $0.199^{\mathrm{a}}$ & $0.201^{\mathrm{b}}$ & 0.139 \\
\hline MSCI World past perf. & $\mathrm{T}$ & 0.020 & $0.036^{\mathrm{a}}$ & 0.024 & -0.006 & -0.041 \\
\hline Size spread & $\mathrm{T}$ & $0.375^{\mathrm{a}}$ & $0.109^{\mathrm{a}}$ & $0.215^{\mathrm{a}}$ & 0.153 & 0.013 \\
\hline Value spread & $\mathrm{T}$ & -0.138 & 0.040 & 0.086 & 0.127 & 0.078 \\
\hline Momentum spread & A & -0.075 & -0.030 & -0.047 & 0.122 & 0.092 \\
\hline Contrarian spread & A & -0.142 & 0.000 & -0.009 & -0.081 & 0.054 \\
\hline TF equities & A & 0.104 & -0.026 & 0.085 & $0.405^{\mathrm{a}}$ & $0.315^{\mathrm{a}}$ \\
\hline \multicolumn{7}{|l|}{ IR risk } \\
\hline Change $10-y r$ US Govt yield & $\mathrm{T}$ & $-1.799^{b}$ & $-1.743^{\mathrm{a}}$ & $-1.664^{\mathrm{b}}$ & $-2.668^{\mathrm{a}}$ & 0.235 \\
\hline TF interest rates & A & -0.034 & $-0.066^{\mathrm{b}}$ & -0.009 & 0.028 & $0.404^{\mathrm{a}}$ \\
\hline Change high yield spread & A & -0.642 & $-1.713^{\mathrm{a}}$ & $-2.213^{\mathrm{a}}$ & $-1.700^{\mathrm{b}}$ & 1.206 \\
\hline \multicolumn{7}{|l|}{ Other } \\
\hline TF currencies & A & 0.056 & 0.011 & -0.037 & 0.092 & $0.555^{\mathrm{a}}$ \\
\hline TF commodities & A & -0.106 & -0.031 & -0.125 & 0.083 & $0.577^{\mathrm{a}}$ \\
\hline \multicolumn{7}{|l|}{ Adj. $R^{2}$} \\
\hline Full set of factors & & 0.77 & 0.68 & 0.69 & 0.60 & 0.68 \\
\hline Traditional risk factors & & 0.76 & 0.48 & 0.62 & 0.38 & 0.09 \\
\hline$F$-Statistic of alternative risk factors & & 1.51 & $7.09^{\mathrm{a}}$ & $3.37^{\mathrm{a}}$ & $6.21^{\mathrm{a}}$ & $19.17^{\mathrm{a}}$ \\
\hline
\end{tabular}

Estimation period: January 1994-December 1999.

Three digit numbers are betas from the multivariate regression.

${ }^{a}$ Significant at 1 per cent, ${ }^{b}$ significant at 5 per cent.

and the fact that it increases, clearly outlines the growing importance of the dynamic aspect of hedge funds.

The set of risk factors enables us to capture the differences in risk exposures across the HF style indices. As expected, HFRI EH is mostly exposed to equity risk factors. Arbitrage strategies exhibit low exposures to a broad set of risk factors. Directional strategies have high exposures to trend following risk factors, showing evidence of their dynamic long-term positioning on a large set of markets.

Risk exposures vary across both time periods, showing that hedge fund managers allocate to the various sources of risk dynamically. We observe changes in the equity risk exposures (in both 
Table 3: Regression results - May 2000-July 2007

\begin{tabular}{lcccccr}
\hline $\begin{array}{l}\text { Risk factors (T=traditional, A=alternative) } \\
\text { Alpha annualised }\end{array}$ & $\begin{array}{l}\text { HFRI EH } \\
1.88 \%\end{array}$ & $\begin{array}{l}\text { HFRI RVA } \\
5.92 \%^{\mathrm{a}}\end{array}$ & $\begin{array}{l}\text { HFRI ED } \\
5.0 \%^{\mathrm{a}}\end{array}$ & $\begin{array}{l}\text { HFRI Macro } \\
4.48 \%^{\mathrm{a}}\end{array}$ & $\begin{array}{l}\text { Stark MF } \\
1.13 \%\end{array}$ \\
\hline $\begin{array}{l}\text { Equity risk } \\
\text { MSCI World }\end{array}$ & $\mathrm{T}$ & $0.407^{\mathrm{a}}$ & $0.055^{\mathrm{a}}$ & $0.236^{\mathrm{a}}$ & $0.183^{\mathrm{a}}$ & 0.048 \\
MSCI World past perf. & $\mathrm{T}$ & 0.010 & 0.003 & $0.011^{\mathrm{b}}$ & 0.005 & 0.005 \\
Size spread & $\mathrm{T}$ & $0.235^{\mathrm{a}}$ & 0.012 & $0.188^{\mathrm{a}}$ & $0.151^{\mathrm{a}}$ & 0.119 \\
Value spread & $\mathrm{T}$ & 0.006 & 0.023 & $0.082^{\mathrm{b}}$ & 0.015 & 0.020 \\
Momentum spread & $\mathrm{A}$ & $0.069^{\mathrm{a}}$ & 0.021 & $0.044^{\mathrm{b}}$ & 0.019 & 0.017 \\
Contrarian spread & $\mathrm{A}$ & 0.005 & 0.023 & 0.012 & -0.030 & -0.070 \\
TF equities & $\mathrm{A}$ & $0.072^{\mathrm{b}}$ & $0.082^{\mathrm{a}}$ & 0.048 & $0.103^{\mathrm{b}}$ & $0.241^{\mathrm{a}}$
\end{tabular}

IR risk

Change 10-yr US Govt yield

$\mathrm{TF}$ interest rates

Change high yield spread

$\begin{array}{rrrrrr}\mathrm{T} & -0.721 & -0.712^{\mathrm{a}} & -1.083^{\mathrm{a}} & -1.630^{\mathrm{a}} & -1.690^{\mathrm{b}} \\ \mathrm{A} & 0.016 & 0.013 & 0.028 & 0.125^{\mathrm{a}} & 0.381^{\mathrm{a}} \\ \mathrm{A} & -0.240 & -0.585^{\mathrm{a}} & -0.991^{\mathrm{a}} & -0.007 & 0.161\end{array}$

Other

$\begin{array}{lrrrrrr}\text { TF currencies } & \text { A } & -0.012 & -0.022 & 0.005 & 0.139^{\mathrm{a}} & 0.344^{\mathrm{a}} \\ \text { TF commodities } & \text { A } & 0.029 & 0.017 & -0.015 & 0.160^{\mathrm{a}} & 0.335^{\mathrm{a}}\end{array}$

Adj. $R^{2}$

Full set of factors

Traditional risk factors

F-Statistic for alternative risk factors

\begin{tabular}{llllc}
0.85 & 0.49 & 0.80 & 0.57 & 0.70 \\
0.82 & 0.22 & 0.75 & 0.27 & 0.06 \\
$3.48^{\mathrm{a}}$ & $7.12^{\mathrm{a}}$ & $3.84^{\mathrm{a}}$ & $9.28^{\mathrm{a}}$ & $26.23^{\mathrm{a}}$ \\
\hline
\end{tabular}

Estimation period: May 2000-July 2007.

Three digit numbers are betas from the multivariate regression.

${ }^{\mathrm{a}}$ Significant at 1 per cent, ${ }^{\mathrm{b}}$ significant at 5 per cent.

traditional and alternative betas), and a decrease in the exposure to changes in long-term interest rates and to changes in high yield spreads.

\section{Alternative risk exposures as correlation drivers}

In this section, we test the hypothesis that alternative strategies implemented by hedge funds are among the main drivers of their correlation to traditional investments. First, we decompose hedge fund returns in order to separate the contribution stemming from exposures to alternative risk factors from that of traditional risk exposures. Secondly, we analyse the correlation pattern of each of the return contributions to traditional investments. 


\section{Alternative vs traditional contribution to hedge fund returns}

Based on the factor decomposition framework, we rearrange equation (1) in order to separate the return contribution of alternative risk exposures from that of traditional risk exposures. We assume that the performance not explained by alternative risk factors is the return contribution of traditional risk factors, which is a conservative assumption. If we are missing an alternative risk factor, its contribution to the performance will be considered as traditional. Formally, the performance is decomposed as follows:

$$
\begin{aligned}
R_{i, t} & =\sum_{m} \beta_{i, m}^{\text {alter }} R_{m, t}^{\text {alter }} \\
& +\left(\alpha_{i}+\sum_{n} \beta_{i, n}^{\text {trad }} R_{n, t}^{\text {trad }}+\varepsilon_{i, t}\right) \\
& =A C_{i, t}+T C_{i, t}
\end{aligned}
$$

where

$$
A C_{i, t}=\sum_{m} \beta_{i, m}^{\text {alter }} R_{m, t}^{\text {alter }}
$$

is the contribution of alternative risk factors to the performance of index $i$, at time $t$. It corresponds to the sum of individual alternative risk factor contributions to index performance.

$$
\begin{aligned}
T C_{i, t} & =\left(\alpha_{i}+\sum_{n} \beta_{i, n}^{\text {trad }} R_{n, t}^{\text {trad }}+\varepsilon_{i, t}\right) \\
& =R_{i, t}-A C_{i, t}
\end{aligned}
$$

is the traditional contribution to the performance of index $i$, at time $t$. It corresponds to the remaining part of the total performance that is not explained by alternative risk exposures.

As we have shown in the previous section, hedge funds change their risk exposures dynamically over time. Therefore, in the remainder of the paper we compute alternative and traditional contributions to performance on a 24-month rolling basis.

It is expected that the correlation of hedge funds to traditional equities is mainly driven by alternative equity strategies and the correlation to traditional bonds by alternative interest rate strategies. Therefore, we compute the return contribution of alternative risk exposures separately for equities and interest rates, using specific sets of alternative risk factors. In that manner, we reduce the number of independent variables in the regressions. The set of alternative equity risk factors includes momentum spread, contrarian spread, and trend following equities, ${ }^{9}$ whereas trend following interest rates and changes in high yield spreads are the alternative interest rate risk factors.

For each 24-month window, we obtain four series of 24 monthly contributions to performance: (a) return contribution of alternative equity risk exposures, (b) return contribution of alternative interest rate risk exposures, (c) traditional return contribution with respect to nonalternative equity risk exposures, and (d) traditional return contribution with respect to nonalternative interest rate risk exposures.

\section{Correlations implied by alternative and traditional risk exposures}

We compute two types of implied 24-month rolling correlations. Firstly, correlations implied by alternative risk exposures are computed between the return contributions of alternative risk exposures and the corresponding traditional investment performance. Secondly, the traditional return contributions are used to 



Figure 2: (a) Twenty-four-month rolling measured correlations of HF style indices to world equities; (b) 24-month rolling implied alternative equity correlations; (c) 24-month rolling implied traditional equity correlations

compute the correlations implied by traditional risk exposures.

In order to outline the impact of hedge funds' dynamics on measured correlations, we show three correlation charts per asset class (equities and bonds). The first chart presents the 24month rolling measured correlations of HF style indices to the traditional investment index. The next two charts present the implied alternative correlations and the implied traditional correlations of HF style indices to the traditional investment index, respectively.

Correlations of hedge fund style indices to traditional equities are presented in Figure 2a (measured correlations), Figure 2b (implied alternative equity correlations), and Figure 2c (implied traditional equity correlations).
Measured correlations of all hedge fund style indices to traditional equities have increased over the last three years, to reach their peak at the end of 2006 (see Figure 2a). Since then, they have started to decrease, especially for HFRI Macro and Stark MF. Measured correlations to traditional equities vary over time. Temporarily, their level can be high. All hedge fund styles having high correlations to traditional equities at the same time, as it is the case between 2004 and 2006, is a new feature.

In Figure 2b, the implied alternative equity correlations of hedge fund styles to traditional equities also reach a high level (between 0.7 and 0.8 ) at the end of 2004 and stabilise over the following years. This pattern during the recent past supports the hypothesis that correlations of 
hedge funds to traditional investments are driven by the dynamic behaviour of hedge fund managers. During the recent bull period on equity markets (starting in 2003), alternative equity strategies have positioned themselves to profit from the good performance of equities. For instance, a trend following strategy takes long positions on a diversified set of equity futures markets. Implied alternative equity correlations have a pattern close to that of the 'perfect timing' hedge fund shown in Section 1 (see Figure 1). This similarity is an additional piece of evidence that dynamic strategies of hedge funds drive their correlations to traditional investments. Therefore, we refute the hypothesis that hedge funds have lost their diversification benefits.

Implied traditional equity correlations do not increase over the last three years (see Figure 2c).
They remain in a range between 0.2 and 0.6 , each hedge fund style having its individual level. Furthermore, implied traditional equity correlations have been decreasing since 2006. Their recent evolution is a strong piece of evidence supporting the hypothesis that correlations to traditional investments are driven by dynamic strategies implemented by hedge funds. This finding is also a robustness check of our factor decomposition methodology.

Correlations to traditional bonds are presented in the next three figures: rolling measured correlations in Figure 3a, rolling implied alternative interest rate correlations in Figure 3b, and rolling implied traditional interest rate correlations in Figure 3c. Measured correlations to traditional bonds are on average slightly
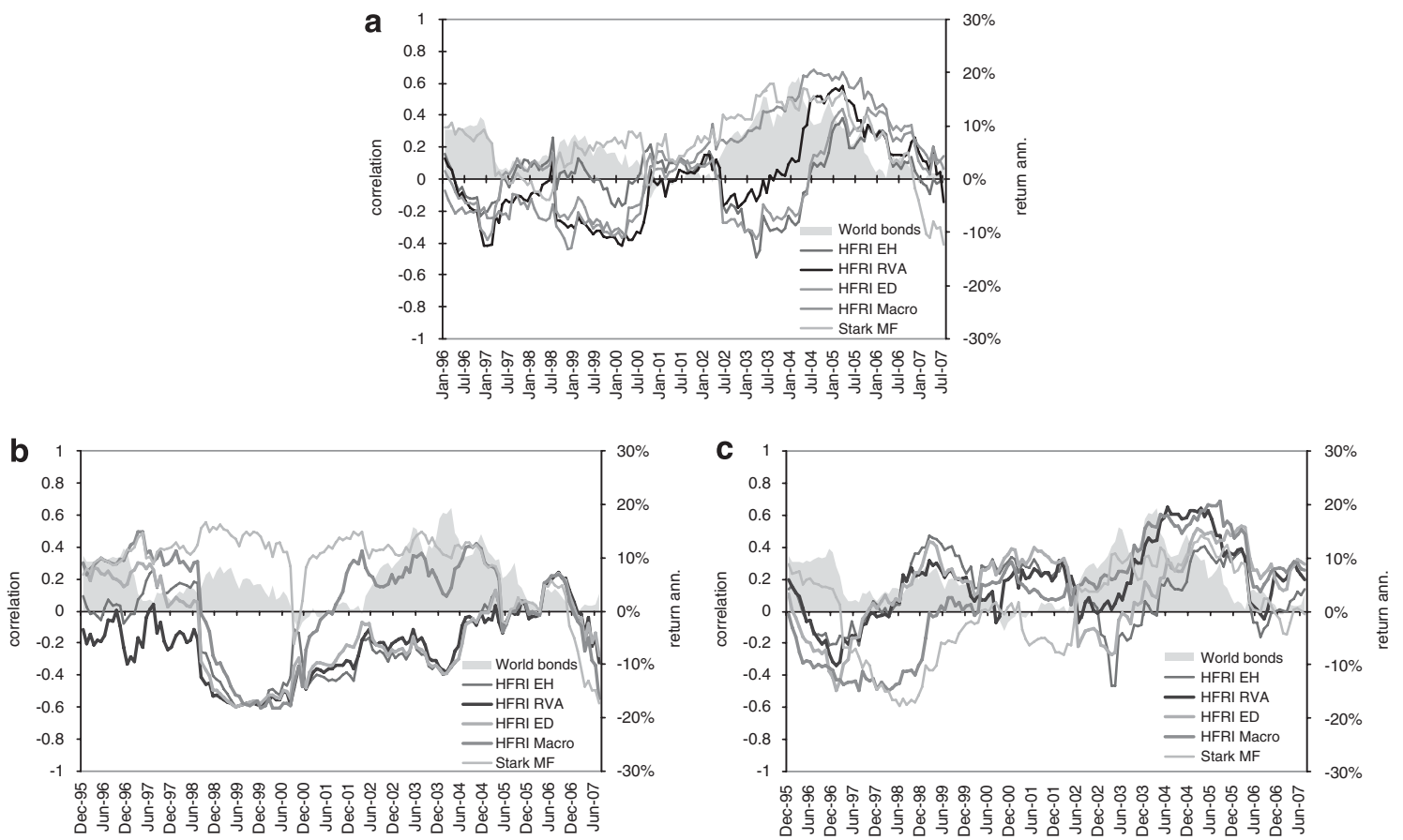

Figure 3: (a) Twenty-four-month rolling measured correlations of HF style indices to world bonds; (b) 24-month rolling implied alternative interest rate correlations; (c) 24-month rolling implied traditional interest rate correlations 
negative for most hedge fund styles managed futures being an exception (see Figure 3a). They have increased during the period between 2002 and 2004 to benefit from the rally in bond markets. Figure $3 \mathrm{c}$ clearly illustrates this pattern. When returns on bonds are high, implied traditional interest rate correlations tend to increase, and conversely when returns are low. In other words, all hedge fund styles adjust their exposure to changes in interest rates (the main traditional risk exposure).

Focusing on the recent evolution of measured correlations to bonds, we notice a strong decrease, which is explained in a first step by implied traditional correlations (2004-2005) and in a second step by implied alternative correlations (2006 to present). In fact, if measured correlations are close to or below zero, it is mainly due to implied alternative correlations, as implied traditional correlations tend to slightly increase again since 2006. Similar to equities, the recent level of correlations to bonds is mainly explained by the alternative interest rate strategies implemented by hedge funds. This finding refutes the hypothesis that hedge funds have lost their diversification potential.

The pattern of implied alternative interest rate correlations is especially interesting. There is a distinction between managed futures and global macro on one side and the other hedge fund styles on the other side. Equity hedged, relative value, and event driven exhibit low and negative implied traditional correlations to bonds over the full period. In a low interest rate environment, they do not seem to be exposed to alternative interest rate risk factors. Their main risk allocations are to other types of strategies and asset classes not captured by the alternative interest rate risk factors of the model.
We observe more active patterns for managed futures and global macro. Managed futures show positive implied alternative interest rate correlations until 2004. Over that period, they were profiting from the down-trend in interest rates. Global macro managers exhibit large variations in their implied alternative interest rate correlations. The broad range of actively managed directional strategies they are implementing makes them change their exposure to fixed income factors. Major changes occur after the Russian crisis in 1998, during the equity bear market and rally on bonds in 2000 to 2003, and after the reversal in the evolution of interest rates in 2004.

Overall, the evolution of correlations to bonds is consistent with our hypothesis that dynamic strategies implemented by hedge funds drive correlations. There is, however, a difference between correlations to equities and correlations to bonds. On the one hand, alternative equity strategies influence the correlations of all hedge fund styles and are the main driver of their evolution. On the other hand, our set of alternative interest rate risk factors only enables us to capture the dynamics of two hedge fund styles (managed futures and global macro). Other hedge fund styles may have low exposures to alternative interest rate strategies (equity hedged), exposures to strategies not captured by our factors (fixed income arbitrage in relative value), and/or exposures that become significant only in extreme conditions (distressed securities in event driven).

\section{CONCLUSION}

Measured correlations are a static view of the relationships between two series of data. Hedge funds implement dynamic strategies with a 
dynamic allocation to risk factors. Measured correlations between a 'perfect timing' hedge fund strategy and world equities is time-varying and could temporarily be very high with respect to the stock market environment. Actually, the instantaneous correlations are either +1 or -1 . By construction, the 'perfect timing' hedge fund strategy is a perfect hedge when the stock market is down. Measured correlations are misleading in expressing the diversification potential of dynamic strategies such as those employed by hedge funds.

We developed a framework to identify the drivers of correlations between hedge funds and traditional investments. Alternative risk factors partially integrate the dynamics of hedge fund strategies in their payoff structure. They contribute significantly in explaining variations in hedge fund returns. Therefore, we use their contribution to hedge fund performance as a proxy for the dynamics of hedge fund strategies. We find that it is an important driver of the current high correlations to world equities.

The part of hedge fund performance that is not explained by the alternative risk factors exhibits a different correlation pattern to traditional investments. Implied traditional correlations to traditional investments are more stable over time than those based on alternative risk factors. They give additional evidence that the dynamics of hedge fund strategies is well captured by alternative risk factors.
Our analysis clearly shows that correlations of hedge funds with traditional investments are driven by the dynamic components of alternative investment strategies. We reject the hypothesis that hedge funds are no longer providing diversification to traditional investments. Measured correlations are biased by the ability of hedge funds to adjust to current market conditions.

\section{References and Notes}

1 Lo, A. (2001) 'Risk Management for Hedge Funds: Introduction and Overview', Financial Analyst Journal, Vol. 57, pp. 16-33.

2 Fung, W. and Hsieh, D.A. (2004) 'Hedge Fund Benchmarks: A Risk Based Approach', Financial Analyst Journal, Vol. 60, pp. 65-80.

3 Agarwal, V., Fung, W., Loon, Y.C. and Naik, N.Y. (2006) 'Risk and Return in Convertible Arbitrage: Evidence from the Convertible Bond Market', Working paper, EFA 2006 Zurich Meetings, available at SSRN.

4 Fung, W. and Hsieh, D.A. (2001) 'The Risk in Hedge Fund Strategies: Theory and Evidence from Trend Followers', Review of Financial Studies, Vol. 14, pp. 313-341.

5 Mitchell, M. and Pulvino, T. (2001) 'Characteristics of Risk in Risk Arbitrage', Journal of Finance, Vol. 56, pp. 2135-2175.

6 Lequeux, P. and Acar, E. (1998) 'A Dynamic Index for Managed Currencies Funds Using CME Currency Contracts', European Journal of Finance, Vol. 4, pp. 311-330.

7 Bacmann, J.-F. and Jeanneret, P. (2005) 'Funds of Funds are Still Providing Alpha', Spring, Hedgequest.

8 For a more detailed definition of the risk factors, see ref. [7] above.

9 We find similar results by adding MSCI World past performance, Size spread, and Value spread to the set of equity risk factors. 